\title{
MEMAHAMI PERJALANAN "KAMPUNG CYBER" MELALUI LENSA ACTOR NETWORK THEORY
}

\author{
Alfandya*1, Fathul Wahid ${ }^{2}$ \\ ${ }^{1,2}$ Universitas Islam Indonesia, Yogyakarta \\ Email: ${ }^{1}$ alfandya95@gmail.com, ${ }^{2}$ fathul.wahid@uii.ac.id \\ *Penulis Korespondensi
}

(Naskah masuk: 20 Mei 2020, diterima untuk diterbitkan: 15 November 2021)

\begin{abstract}
Abstrak
Penelitian terdahulu menunjukkan tingginya risiko kegagalan dari proyek-proyek penerapan teknologi informasi dan komunikasi (TIK) untuk pembangunan. Salah satu tantangan utamanya adalah mendapatkan kepercayaan dari masyarakat dan memastikan bahwa program-program itu lestari. Penelitian ini akan membahas detail proses implementasi TIK untuk pembangunan menggunakan lensa Actor Network Theory. Detail proses implementasi TIK nantinya akan dianalisis berdasarkan fase-fase pada Actor Network Theory. Studi kasus penelitian ini adalah sebuah desa bernama "Kampung Cyber" di Yogyakarta yang sudah menerapkan TIK sejak tahun 2008. Penelitian ini merupakan hasil dari studi kualitatif berdasarkan wawancara dan observasi dari masyarakat Kampung Cyber beserta dengan tokoh-tokoh utama dalam implementasi TIK. Detail temuan penelitian ini dapat dijadikan referensi dalam implementasinya di daerah lain. Hasil penelitian menunjukkan Actor Network Theory mampu memetakan bagaimana proses implementasi TIK di Kampung Cyber. Hasil analisis juga menunjukkan perubahan peran Ketua RT yang di masa awal menjadi sangat dominan, yang akhirnya digantikan oleh masyarakat.
\end{abstract}

Kata kunci: Actor Network Theory, teknologi informasi dan komunikasi untuk pembangunan, implementasi TIK.

\section{UNDERSTANDING THE TRAJECTORY OF "KAMPUNG CYBER" THROUGH THE LENS OF ACTOR NETWORK THEORY}

\begin{abstract}
Previous studies have documented failures in various information and communication technology for development (ICT4D) projects. One of the main challenges in ICT4D project is gaining the trust of the community and ensuring its sustainability. This paper presents stories from ICT4D project implementation through the lens of Actor Network Theory (ANT). The case is a village called "Kampung Cyber" in Yogyakarta. This study employs a qualitative approach using data gathered from interviews with the main actors and observations in Kampung Cyber. Details from the findings may be adapted as a reference to ICT4D project implementation in similar context. The finding unveil that the theory is very useful to explain the implementation process along with involved actors. The study also finds that the role of the leading actor (i.e. the head of neighborhood unit)) diminishes over time and the dominant role is taken over by the community.
\end{abstract}

Keywords: Actor Network Theory, information communication technology for development, ICT Implementation.

\section{PENDAHULUAN}

Secara luas disepakati bahwa teknologi informasi dan komunikasi (TIK) dapat memainkan peran penting dalam pengembangan negara-negara berkembang pada umumnya, khususnya masyarakat terpencil (Aitkin, 2009; Heeks and Kanashiro, 2009). TIK untuk pembangunan atau information technology for development (ICT4D) merupakan salah satu bentuk program penerapan teknologi dalam meningkatkan pembangunan berbagai sektor. Penerapan TIK untuk pembangunan dapat mengurangi tingkat kesenjangan digital di daerah terpencil. TIK juga memberikan peluang dalam meningkatkan kehidupan masyarakat dalam berbagai sektor seperti sosial, ekonomi, pendidikan, pemerintahan, dan lain sebagainya. Pemerintah Indonesia sendiri menyadari pentingnya pemerataan akses TIK, khususnya Internet. Dari hal tersebut pemerintah Indonesia melalui kominfo mencanangkan program Internet masuk desa/desa Internet (Komunikasi, 2019). 
Proyek-proyek implementasi TIK untuk pembangunan memiliki risiko kegagalan yang cukup tinggi (Awowi, 2010; Marais, 2011; Pitula, DysartGale and Radhakrishnan, 2010). Salah satu bentuk kegagalan adalah ketika hasil implementasi TIK tidak dapat digunakan/diadopsi dengan baik (Awowi, 2010). Keberlanjutan implementasi TIK yang terhenti juga dapat dikatakan kegagalan implementasi (Sanner and Sæbø, 2014), atau dari implementasi teknologi tersebut memberikan dampak negatif yang tidak diinginkan secara serius (Ibrahim-dasuki, Abbott and Kashefi, 2012). Penerapan ICT4D tidak hanya pada implementasi infrastruktur TIK yang mendukung. Memang infrastruktur penting dalam penerapan ICT4D, tetapi terdapat beberapa faktorfaktor lain yang mempengaruhi keberhasilan penerapan proyek berbasis TIK. Khususnya untuk program desa Internet, bagaimana tanggapan dan kemauan masyarakat terkait dengan kebijakan tersebut akan sangat berpengaruh. Infrastruktur yang tersedia tetapi kemauan dari masyarakat sendiri kurang mendukung maka akan mengakibatkan ketidakberhasilan. Pengaruh dari aktor utama dalam implementasi TIK memiliki andil yang besar dalam keberhasilannya (Thapa, 2012). Menganalisis bagaimana pendekatan yang dilakukan kepada masyarakat dalam mengenalkan teknologi informasi juga menjadi perhatian.

Penelitian-penelitian yang membahas mengenai implementasi TIK untuk pembangunan di Indonesia masih belum cukup banyak, khususnya terkait desa internet dengan mengambil sudut pandang pada aktor utama dalam proses implementasinya. Penelitianpenelitian yang membahas mengenai implementasi TIK untuk pembangunan kurang membahas mengenai detail aktivitas-aktivitas yang dapat berwujud pada dampak dari implementasi teknologi tersebut (Harris, 2016). Penelitian ini menjadi menarik karena perbedaan kultur budaya berpengaruh terhadap implementasi dan penerapan teknologi informasi (Sriwindono and Yahya, 2012). Budaya dan kebiasaan dari studi kasus penelitian ini mungkin akan berbeda dengan lokasi lainnya, hal tersebut dapat menimbulkan pengetahuan baru. Kesenjangan tersebut yang menjadi peluang penelitian ini dilakukan.

Penelitian ini bertujuan untuk mengidentifikasi bagaimana detail proses implementasi TIK sehingga dapat dijadikan referensi dalam implementasinya di daerah lain. Mengetahui bagaimana peran dan aktivitas dari aktor utama/orang yang berperan penting dalam keberhasilan implmentasi TIK. Studi kasus dari penelitian ini adalah Kampung Cyber Yogyakarta. Kampung Cyber merupakan sebuah desa di Kota Yogyakarta yang mengimplementasikan TIK untuk mendukung pembangunan di daerahnya. TIK di Kampung Cyber sudah diterapkan sejak tahun 2008, dan berkelanjutan hingga saat ini.

Penelitian ini menggunakan Actor Network Theory (ANT) untuk menganalisis bagaimana implementasi TIK di Kampung Cyber. Actor Network Theory mampu menjabarkan banyak wawasan bagaimana proses yang terjadi selama penerapan teknologi informasi (Andrade and Urquhart, 2010). Lebih lanjut lagi, Actor Network Theory juga mampu menggambarkan bagaimana peran aktor-aktor utama dalam melakukan perubahan terkait dengan implementasi teknologi pada lingkungannya. Detail aktivitas aktor-aktor selama implementasi TIK dapat dianalisis dengan baik melalui Actor Network Theory. Penelitian yang dilakukan oleh Thapa menggunakan ANT untuk menganalisis implementasi TIK di pegunungan Nepal dan juga di pedesaan Kamboja (Thapa, 2011; Luo and Chea, 2017).

Rumusan masalah yang ingin dijawab dalam penelitian ini adalah bagaimana proses implementasi teknologi informasi untuk pembangunan di Kampung Cyber. Paper ini akan dibagi menjadi empat bagian. Pertama membahas mengenai pendahuluan. Pada bagian kedua akan membahas mengenai metode penelitian yang digunakan dalam penelitian ini. Bagian ketiga berisi hasil dan pembahasan. Bagian keempat adalah kesimpulan dari penelitian ini.

\section{METODE PENELITIAN}

Pada bagian ini akan dibagi menjadi 3 sub bab. Sub bab pertama akan menjelaskan mengenai studi kasus penelitian ini dilakukan. Sub bab kedua akan menjelaskan mengenai teori yang digunakan dalam penelitian ini. Sub bab ketiga akan membahas mengenai bagaimana analisis data dijelaskan.

\subsection{Studi Kasus Penelitian}

Penelitian ini mengambil studi kasus di sebuah desa yang sudah mengimplementasikan TIK yaitu Kampung Cyber. Kampung Cyber ini memiliki cakupan satu RT yang berada di kota Yogyakarta. Lokasi Kampung Cyber tepatnya berada di Patehan kecamatan Kraton Kota Yogyakarta. Kampung Cyber berada di kawasan situs peninggalan Kraton Yogyakarta yaitu Pemandian Taman Sari. Obyek wisata Pemandian Taman Sari merupakan salah satu objek wisata yang tidak pernah sepi oleh pengunjung, baik wisatawan dalam negeri dan mancanegara. Dipilihnya Kampung Cyber dalam penelitian implementasi TIK untuk pembangunan karena Kampung Cyber sudah mulai menerapkan TIK di desa sejak tahun 2008. Sejak 2008 hingga saat ini di Kampung Cyber juga memiliki keberlanjutan implementasi yang baik. Selain hal itu berbagai dampak positif dari implementasi TIK juga dirasakan oleh masyarakat. Dari hal itu Kampung Cyber dirasa sesuai sebagai studi kasus penelitian ini.

Implementasi TIK di Kampung Cyber dilakukan swadaya oleh masyarakat sendiri. Semua infrastruktur dan juga biaya untuk berlangganan internet dari masyarakat Kampung Cyber. Salah satu tujuan diimplementasikan TIK adalah sebagai sarana 
untuk memberdayakan masyarakat. TIK diharapkan dapat membuka dan meningkatkan potensi masyarakat sehingga dapat meningkatkan kesejahteraan masyarakat, peluang tersebut yang ingin memotivasi masyarakat untuk mengimplementasikan dan belajar mengenai TIK.

Masyarakat Kampung Cyber sendiri mayoritas memiliki pekerjaan sebagai wirausaha. Masyarakat di Kampung Cyber memang dari awal banyak yang memiliki usaha sebagai pembatik, bukan hanya di Kampung Cyber masyarakat di sekitar wilayah tersebut memang mayoritas sebagai pembatik. Sebagian warga mengirimkan hasil batiknya kepada pengepul, dan ada juga yang membuat toko sendiri di Kampung Cyber. Selain sebagai pembatik masyarakat juga memiliki usaha lain seperti kedai kopi, penjual peralatan pancing, pengrajin kumis palsu, penjual angkringan, dan sebagainya. Salah satu bentuk implementasi TIK yang bermanfaat bagi masyarakat Kampung Cyber adalah masyarakat yang kini menggunakan sosial media dalam mengenalkan produk jualannya seperti batik, usaha pancing, dan lainnya. Masyarakat Kampung Cyber yang dulunya sama sekali tidak mengetahui mengenai teknologi informasi sekarang sudah dapat memanfaatkannya. Sistem informasi warga yang digunakan untuk mempermudah pelayanan RT, RW dan kelurahan kepada masyarakat juga sudah diimplementasikan di Kampung Cyber.

Implementasi TIK yang dilakukan di kampung cyber adalah secara bertahap, karena batasan biaya dan juga masyarakat yang pada saat itu sama sekali belum mengetahui mengenai komputer. Bentuk TIK adalah terkoneksinya satu area Kampung Cyber dengan Internet. Masing-masing rumah warga terkoneksi dengan internet dengan pembagian bandwidth yang merata. Koneksi wifi juga tersedia khusus untuk masyarakat, selain itu Kampung Cyber juga menyediakan wifi gratis bagi wisatawan. Areaarea yang strategis di Kampung Cyber juga dipantau oleh CCTV yang dapat diakses oleh masyarakat untuk memantau keamanan. Selain bentuk infrastruktur di Kampung Cyber juga diadakan berbagai pelatihan untuk memaksimalkan potensi infrastruktur yang ada. Kondisi masyarakat yang sama sekali tidak tahu terkait teknologi informasi membuat pelatihan-pelatihan menjadi penting.

\subsection{Actor Network Theory}

Pemilihan ANT sebagai lensa analisis didasari oleh penelitian yang dilakukan oleh Sein, Thapa, Hatakka, \& Sæbø (Sein et al., 2018). Berdasarkan penelitian tersebut, penerapan teknologi informasi dan komunikasi di bagi menjadi 3 perpektif yaitu, ICT, proses transformasi, dan dampak pengembangannya. Teori-teori yang digunakan yaitu Affordance untuk ICT, Actor Network Theory untuk proses transformasi, dan Capability Approach untuk dampak pengembangannya (Sein et al., 2018). Setiap teori yang digunakan memiliki kencenderungan sudut pandang kepada hal tertentu. Penting untuk menentukan teori yang sesuai dalam melakukan suatu penelitian, kesalahan pemilihan teori yang digunakan dapat mengakibatkan interpretasi data tidak sesuai. Berdasarkan penelitian Zheng teori-teori yang dapat dijadikan kunci dan memiliki pengaruh yang kuat dan untuk menguraikan beberapa pemahaman dari ICT4D di lapangan yaitu Diffusion of Innovation, Technology Acceptance Model, Structuration Theory, Actor Network Theory, Institutional Theory, Sustainable Livelihood Framework, dan Capability Approach (Zheng and Holloway, 2019). Actor Network Theory dipilih karena sesuai dengan tujuan penelitian ini untuk melihat proses transformasi implementasi TIK di Kampung Cyber. Berbagai penelitian juga menggunakan ANT untuk melihat proses implementasi. Salah satunya penelitian yang dilakukan oleh Thapa yang menggunakan ANT untuk meneliti implementasi TIK di pegunungan Nepal (Thapa, 2011). ANT digunakan untuk meneliti bagaimana implementasi TIK di pedesaan Kamboja (Luo and Chea, 2017). Teori lain memiliki fokus pendekatan yang berbeda jika dibandingkan dengan ANT. Contohnya adalah Capability Approach yang pada konteks ICT4D lebih berfokus mengenai sumber daya yang diterapkan dan dampak dari sumber daya tersebut (Kleine, 2010).

Actor Network Theory (ANT) dikembangkan dari studi sosiologi dan sains di Ecole des Mines di (Callon, 1986; Latour, 1992; Law and Callon, 1992). Gagasan inti ANT adalah untuk melacak peran aktor manusia dan non-manusia dalam bertindak atau mengilhami orang lain untuk bertindak sebagai mediator untuk menciptakan beberapa bentuk jaringan (Latour, 2005). ANT menggambarkan masyarakat sebagai jaringan sosioteknik (jaringan aktor) di mana objek teknis berpartisipasi dalam terus-menerus membangun jaringan heterogen yang menyatukan berbagai aktor (Murdoch, 1997). Fokus utama ANT, ketika diterapkan dalam konteks implementasi TIK, adalah untuk memahami proses di mana berbagai aktor sosial dan teknis menciptakan dan memperluas jejaring sosial dengan kepentingan yang selaras (Thapa, 2012). Penelitian yang akan dilakukan akan berfokus pada proses translasi menggunakan ANT untuk memahami bagaimana aktor utama dalam memprakarsai proyek desa Internet, mengidentifikasi berbagai aktor, bagaimana mengajak aktor-aktor lain dan dampaknya. Melalui proses translasi pemahaman mengenai bagaimana aktor-aktor dalam implementasi suatu TIK dapat diperoleh lebih terperinci, strategi yang digunakan dan bagaimana masing-masing aktor berkomunikasi dan membentuk suatu hubungan dapat diketahui (Thapa, 2011). Analisis menggunakan ANT akan dibagi menjadi 4 fase yaitu Problematization, Interessement, Enrollment, dan Mobilization. 
Tabel 1. Fase Actor Network Theory

\begin{tabular}{ll}
\hline Fase & Penjelasan \\
\hline Problematization & Fase dimana diidentifikasi permasalahan \\
& yang terjadi dan bagaimana permasalahan \\
tersebut diselesaikan. Obligatory point of & passage juga akan diidentifikasi yaitu \\
tujuan yang ingin dicapai dan disepakati & bersama. \\
& Fase untuk mengidentifikasi bagaimana \\
& mengajak dan membuat aktor lain \\
tnteressement & Fase enrolment akan dianalisis terkait \\
& penerimaan dari masyarakat dan \\
& bagaimana hal yang dilakukan ketika \\
& masyarakat sudah tertarik/berminat pada \\
& implementasi teknologi informasi dan \\
& komunikasi dianalisis \\
& Fase mobilization ini akan dari \\
& bagaimana keberlanjutan \\
& implementasi teknologi informasi. \\
\hline
\end{tabular}

\subsection{Pengumpulan Data}

Pendekatan kualitatif dipilih pada penelitian ini untuk mendapatkan informasi yang lebih detail terkait implementasi TIK di Kampung Cyber. Metode pengumpulan data yang digunakan adalah observasi dan wawancara. Narasumber dari wawancara adalah masyarakat Kampung Cyber dan tokoh-tokoh masyarakat yang berperan dalam implementasi TIK di Kampung Cyber. Observasi dilakukan untuk mengetahui bagaimana infrastruktur yang diimplementasikan di Kampung Cyber. Tabel 2 menunjukkan narasumber dari penelitian ini.

Tabel 2. Narasumber

\begin{tabular}{|c|c|c|c|}
\hline No & Nama & Profesi & $\begin{array}{l}\text { Durasi } \\
\text { Wawancara }\end{array}$ \\
\hline 1 & Pak Heri & Ketua RT Lama & 1 jam \\
\hline 2 & Pak Koko & Ketua RT Baru & 1 jam 15 menit \\
\hline 3 & Lek Wun & Pengrajin Batik & $1 \mathrm{jam}$ \\
\hline 4 & Pak Rudi & Pengrajin Batik & 30 menit \\
\hline 5 & Pak W & $\begin{array}{l}\text { Penjual } \\
\text { Angkringan }\end{array}$ & 40 menit \\
\hline 6 & Pak Nanda & $\begin{array}{l}\text { Pengusaha Kumis } \\
\text { Palsu }\end{array}$ & 40 menit \\
\hline 7 & Pak Supri & Tur Guide & 30 menit \\
\hline 8 & $\begin{array}{l}\text { Bapak penjual } \\
\text { omah pancing }\end{array}$ & $\begin{array}{l}\text { Penjual omah } \\
\text { pancing }\end{array}$ & 40 menit \\
\hline 9 & $\begin{array}{l}\text { Ibu penjual } \\
\text { omah pancing }\end{array}$ & $\begin{array}{l}\text { Penjual omah } \\
\text { pancing }\end{array}$ & 40 menit \\
\hline 10 & Ibu Pembatik & Pengrajin Batik & 20 menit \\
\hline
\end{tabular}

\subsection{Analisis Data Berdasarkan ANT}

Hasil pengumpulan data dari wawancara, observasi, dan rapat RT kemudian di transkripkan. Hasil transkrip dari wawancara observasi tersebut kemudian akan dianalisis dan dikategorikan sesuai dengan fase-fase pada ANT yaitu problematization, interessement, enrolment, dan mobilization.

Fase problematization adalah fase dimana diidentifikasi permasalahan yang terjadi dan bagaimana permasalahan tersebut diselesaikan. Pada fase ini juga akan dianalisis aktor-aktor yang terkait pada implementasi TIK untuk pembangunan. Obligatory point of passage juga akan diidentifikasi yaitu semacam tujuan yang ingin dicapai dan disepakati bersama.

Fase selanjutnya adalah interessment. Setelah aktor dan juga obligatory passage point diidentifikasi, fase selanjutnya adalah bagaimana mengajak dan membuat aktor lain tertarik. Pada bagian ini akan dianalisis proses aktor utama bernegoisasi dan mengajak terkait pelaksanaan solusi dari permasalahan yang sudah diidentifikasi sebelumnya. Aktivitas mengenai bagaimana aktor utama menarik minat masyarakat akan dibahas pada fase ini.

Pada fase enrolment akan dianalisis terkait penerimaan dari masyarakat dan bagaimana hal yang dilakukan ketika masyarakat sudah tertarik/berminat kepada implementasi TIK di Kampung Cyber.

Fase mobilization ini akan dianalisis bagaimana keberlanjutan dari implementasi teknologi informasi. Aktivitas-aktivitas yang merupakan bentuk implikasi dari TIK akan dibahas pada fase ini. Keberlanjutan implementasi jangka panjang merupakan salah satu bentuk keberhasilan implementasi teknologi informasi.

Berdasarkan fase-fase yang sudah memiliki fokus analisis masing-masing, hasil transkrip dari pengumupulan data akan di kelompokkan sesuai dengan fase pada ANT. Pengelompokan hasil transkrip pengumpulan data itu nantinya akan dianalisis dan diketahui bagaimana proses implementasi TIK di Kampung Cyber.

\section{HASIL DAN PEMBAHASAN}

Bagian ini akan dibahas mengenai hasil temuan secara terperinci dari penelitian ini. Bagian hasil dan pembahasan ini akan dibagi menjadi 2 bagian. Pada bagian pertama membahas implementasi TIK untuk pembangunan menggunakan ANT. Bagian kedua merupakan diskusi atau bahasan mengenai implementasi TIK yang sudah dikategorikan pada masing-masing fase.

\subsection{TIK untuk Pembangunan ANT}

Bagian ini akan membahas proses implementasi TIK untuk pembangunan studi kasus Kampung Cyber dari sudut pandang ANT. Pembahasan ini akan dibagi menjadi 4 bagian sesuai dengan fase pada ANT.

\subsubsection{Problematization}

Pada bagian problematization akan membahas mengenai siapa aktor utama dan bagaimana masalah yang ingin diselesaikan. Pada studi kasus Kampung Cyber, aktor utama dalam implementasi TIK adalah Ketua RT 36 Kampung Cyber itu sendiri. Ketua RT tersebut menjadi aktor utama dalam implementasi TIK karena pada saat itu ketua RT 36 melihat bagaimana kondisi masyarakatnya dalam kondisi yang tidak berkembang stag (hanya seperti itu saja). Berdasarkan hal tersebut ketua RT 36 mencari cara untuk bagaimana meningkatkan kualitas hidup masyarakatnya. Permasalahan tersebutlah yang 
mencetuskan ide dengan mengimplementasikan TIK kepada masyarakatnya. Konsep dasar ANT mencakup aktor (atau actant). Baik objek manusia maupun non-manusia (mis. Teknis) dianggap sebagai aktor. Untuk objek non manusia yang menjadi penggerak implementasi TIK adalah koneksi internet dan juga peran sosial media. Peran internet dan social media akan lebih dibahas di bagian interesment dan enrolment.

Ketua RT 36 menjadi aktor utama dalam implementasi TIK di Kampung Cyber karena Ketua RT 36 lah yang mengurus dan memotori bagaimana implementasi TIK di Kampung Cyber. Sebagai Ketua RT, beliau mengumpulkan jajaran RT seperti sekertaris, dan seksi-seksi lainnya untuk membahas bagaimana proses penerapan TIK di Kampung Cyber. Dalam perancangan strategi warga/masyarakat tidak dilibatkan karena dalam hal tersebut posisinya warga tidak mengetahui apa itu TIK.

Ketua RT: "Ide mengimplementasikan TIK karena kami ingin meningkatkan kesejahteraan rakyat melalui media teknologi informasi informasi dan komunikasi."

Obligatory point of passage yang dari implementasi TIK adalah peningkatan kesejahteraan masyarakat melalui TIK. Tujuan tersebut yang selanjutkan ditekankan kepada masyarakat dalam hal implementasi teknologi informasi yang akan dilakukan di Kampung Cyber.

\subsubsection{Interessement}

Pada bagian ini adalah fase interessement yang akan menjelaskan mengenai bagaimana aktor utama menarik minat dan bernegosiasi dengan aktor-aktor lain dalam implementasi TIK di Kampung Cyber.

Setelah aktor utama atau dalam hal ini berdiskusi dengan perangkat RT lainnya mengenai rencana dan strategi dalam implementasi TIK, tahap selanjutnya yang menjadi pertanyaan adalah bagaimana menarik minat warga/masyarakat untuk bersedia dalam menerapkan TIK. Perlu ditekankan sebelumnya pada saat implementasi TIK Kampung Cyber yaitu pada tahun 2008 penyebaran informasi mengenai teknologi masing sangat minim. Pada saat itu posisinya masyarakat kampung cyber sendiri belum mengetahui apa dan bagaimana cara kerja TIK tersebut. Menjadi tantangan bagaimana aktor utama berdiskusi dan mengajak masyarakat untuk mau belajar TIK.

Strategi pertama yang digunakan aktor utama dalam mengajak masyarakat dalam program implementasi TIK adalah melalui arisan/kumpulan masyarakat. Masyarakat di wilayah RT 36 sendiri memiliki agenda rutin rapat RT dan arisan yang diagendakan satu bulan sekali. Hal tersebut yang dijadikan peluang oleh ketua RT 36 sebagai aktor utama dalam mengajak dan mengenalkan program implementasi TIK kepada masyarakatnya. Selain hal tersebut, ketua RT 36 juga mengajak melalui diskusi terkait manfaat penggunaan internet ketika warga melakukan ronda malam/tugas jaga malam. Acara berkumpulnya masyarakat digunakan oleh ketua RT 36 untuk mengajak dan mengenalkan program TIK yang akan dijalankan. Pendekatan semacam itu dilakukan karena masyarakat sendiri memiliki berbagai kesibukan dan kepentingan, mengadakan acara seperti pengenalan program akan susah untuk dilakukan dan dihadiri oleh masyarakat. Selain itu pembuatan acara pengenalan satu kali tidak akan bisa membuat masyarakat tertarik, mengingat hal tersebut yang relatif asing dan baru. Dengan hal itu aktor utama yaitu ketua RT 36 memilih untuk mengenalkan melalui acara-acara rutin RT dan juga memanfaatkan kesempatan ketika bertemu dan berkumpul dengan masyarakat.

Pada tahap ini memang aktor utama yaitu ketua RT harus melakukan usaha lebih dan secara terus menerus mengajak masyarakatnya. Aktor utama juga diharapkan dipercaya dan dianggap sebagai panutan di wilayahnya. Hal tersebut akan mempermudah dalam mengajak masyarakat.

Masyarakat: " Pertama kali kami diberitahu terkait program implementasi TIK yang akan dilakukan di Kampung Cyber melalui kumpulan rapat RT dan arisan."

Ketua RT: "kami mensosialisasikan dan mengenalkan program penerapan TIK di Kampung Cyber melalui agenda rutin yaitu rapat RT dan arisan setiap bulan. Sosialisasi dilakukan pada agenda tersebut karena susah untuk mencari waktu mengumpulkan warga seluruhnya."

\subsubsection{Enrolment}

Fase selanjutnya adalah enrolment, setelah aktor utama berhasil mengajak masyarakat dalam program penerapan TIK di Kampung Cyber. Hal yang pertama dilakukan adalah melakukan pelatihan pengenalan komputer dan internet, pelatihan komputer dilakukan untuk memberi pemahaman dasar terhadap masyarakat mengenai komputer. Masyarakat pedesaan/tertinggal tentu saja sama sekali tidak mengerti mengenai TIK saat ini. Perlunya pengenalan mengenai komputer, jaringan, hingga penggunaan internet bagi masyarakat tertinggal. Pelatihan tersebut dilakukan selama 1 minggu. Setelah pelatihan pengenalan awal yang dilakukan kepada masyarakat, edukasi terus juga dilakukan. Bentuknya adalah aktor utama yaitu ketua RT mendatangi rumah-rumah warga untuk memberikan pemahaman terkait permasalahan-permasalahan yang mereka rasakan. Pendekatan itu bertujuan agar masyarakat lebih mudah dan lebih cepat dalam mempelajari dan menggunakan Internet.

Masyarakat: "Ketika kami pertama kali diperkenalkan teknologi, kami diberi pelatihan mengenai penggunaan komputer, pengenalan jaringan, dan juga pengenalan mengenai Internet.'

Ketua RT: "Program pertama yang kami lakukan setelah melakukan sosialisasi adalah mengenalkan penggunaan komputer di Lab 
Komputer Atma Jaya. Tujuan dari pengenalan ini adalah agar masyarakat dapat belajar komputer dengan langsung praktek"

Selanjutnya pemasangan komputer di ruang publik dilakukan yaitu di pos ronda. Hal tersebut bertujuan agar masyarakat yang belum memiliki komputer dapat terus belajar. Selain itu hal tersebut juga digunakan untuk menarik minat masyarakat yang belum tertarik untuk belajar komputer dan Internet. Berdasarkan hal ini dapat dilihat bahwa ketika fase enrolment berjalan, fase interesment juga tetap berjalan di Kampung Cyber. Hal tersebut karena tidak semua warga mau ikut belajar ketika interesment awal dilakukan. Fase interesment tetap dilakukan agar seluruh masyarakat dapat berminat belajar komputer dan Internet. Ini berjalan berdampingan dengan Enrolment untuk mengajari masyarakat yang sudah berminat.

Ketua RT: "Tujuan kami memasang komputer di pos ronda adalah agar masyarakat dapat belajar komputer dengan mudah, mengingat pada saat itu komputer bukan hal yang murah yang dapat dimiliki oleh semua masyarakat."

Masyarakat: "Pemasangan komputer di pos ronda membantu kami untuk belajar komputer dan internet, meskipun hanya ada 2 komputer dan harus bergantian tetapi kami tetap antusias untuk belajar.”

\subsubsection{Mobilisation}

Fase mobilisation membahas mengenai bagaimana keberlanjutan dari program implementasi TIK untuk pembangunan Kampung Cyber. Fase mobilisation pada studi kasus di Kampung Cyber ini dilakukan dengan melihat bagaimana penggunaan TIK oleh masyarakat. Tujuannya adalah untuk keberlanjutan implementasi TIK dengan melihat potensi dan kebutuhan masyarakat. TIK memberikan peluang kepada masyarakat untuk dapat dimanfaatkan dalam berbagai hal. Ketua RT dalam hal ini berdiskusi dengan masyarakat dalam berbagai kesempatan seperti rapat, ronda, dan ketika saat dapat berkumpul bersama masyarakat di warung angkringan. Kesempatan itu digunakan untuk berdiskusi mengenai sudut pandang masyarakat, dan juga untuk mengetahui pemanfaatan teknologi yang digunakan. Melalui diskusi tersebut juga dibahas mengenai program-program yang akan dilaksanakan selanjutnya.

Ketua RT mengatakan: "Saya sering berkumpul dengan masyarakat pada berbagai kesempatan untuk mengetahui bagaimana respon masyarakat terhadap implementasi teknologi informasi komunikasi di Kampung Cyber. Dari hal tersebut juga saya sering berdiskusi terkait program yang mungkin dilakukan untuk kedepannya".

Masyarakat mengatakan: "Ketua RT sering berkumpul dengan masyarakat dan berdiskusi pada berbagai kesempatan, hasil diskusi tersebut tidak jarang direalisasikan menjadi program RT."
Berdasarkan hal tersebut dapat dilihat ketika fase mobilisation peran ketua RT hanya sebagai penampung aspirasi dan kebutuhan dari masyarakat. Untuk program keberlanjutan dari implementasi lebih dari kebutuhan dan keinginan masyarakat sendiri. Hal tersebut dapat terjadi ketika masyarakat sudah berada dititik dimana mereka sudah paham cara menggunakan komputer dan browsing melalui internet. Salah satu bentuk program implementasi yang berasal dari kebutuhan masyarakat adalah pelatihan fotografi untuk menunjang nilai barang yang dijual oleh masyarakat.

Ketua RT: "pelatihan fotografi kita adakan dengan melihat kondisi dan kebutuhan masyarakat untuk diajari bagaimana mengambil foto produk yang bagus."

\subsection{Pembahasan}

ANT dapat melacak peran aktor dalam bertindak atau mengilhami orang lain untuk bertindak sebagai mediator untuk menciptakan beberapa bentuk jaringan (Latour, 2005). Hal itu juga ditunjukkan dalam penelitian ini, bagaimana aktor utama dalam mengajak, mengenalkan, mengajarkan dan selanjutnya masyarakat dapat menjadi penentu arah pengembangan dapat dianalisis menggunakan ANT. Gambar 1 menunjukkan bagaimana proses implementasi TIK di Kampung Cyber berdasarkan ANT. Pada fase interesment contohnya, aktor utama melakukan sosialisasi kepada masyarakat melalui pertemuan/rapat rutin dengan warga, melalui obrolan ketika berkumpul. Menunjukkan model pendekatan aktor yang lebih aktif mendatangi warga untuk mengajak dan mengenalkan teknologi informasi pada berbagai kesempatan. Menurut Thapa, ANT juga meningkatkan pemahaman tentang perbedaan dalam metode dan materi yang digunakan oleh para aktor untuk mencapai tujuan individu dan bersama mereka (Thapa, 2011).

Peran berbagai pelaku TIK dan hubungannya antara teknologi dan masyarakat dapat memberi kita lensa yang lebih baik untuk memahami bagaimana TIK dapat digunakan secara efektif untuk meningkatkan mata pencaharian masyarakat miskin dan terpinggirkan (Unwin, 2009). Penelitian ini memberikan sudut pandang lain yaitu melihat bagaimana peran aktor utama dalam implementasi TIK agar implementasi dapat berjalan dengan baik. ANT secara eksplisit membuat kontingensi apakah inovasi tersebut dapat menghasilkan minat di antara pengguna yang dituju (Akrich, Latour and Callon, 2002; Bijker, 1992). Pernyataan tersebut terjawab pada penelitian ini mengenai bagaimana implementasi TIK untuk menarik minat dari pengguna yang dituju dalam hal ini adalah masyarakat.

Analisis ANT membedah sejarah terjemahan proyek ICT4D (Andrade and Urquhart, 2010). Berdasarkan gambar tersebut dapat dilihat pada fase problematization dilakukan pada tahun 2008 sebelum 
Kampung Cyber tersebut diresmikan. Pada fase itu dilakukan diskusi pengurus dan pencetusan ide, pengurus yang berdiskusi adalah kepengurusan RT. Diskusi terkait dengan kondisi masyarakat saat ini dan melihat potensi TIK untuk dapat meningkatkan potensi masyarakat. Setelah hal tersebut langsung masuk ke fase Interessement, fase ini sudah dimulai sebelum Kampung Cyber diresmikan. Hal yang dilakukan adalah melakukan sosialisasi dalam acara pertemuan rutin rapat dan arisan RT setiap bulan. Pada saat itu diumumkan kepada warga mengenai rencana implementasi TIK di Kampung Cyber. Acara tersebut bertujuan agar warga mengerti alasan, tujuan, dan apa implementasi TIK yang dimaksut.

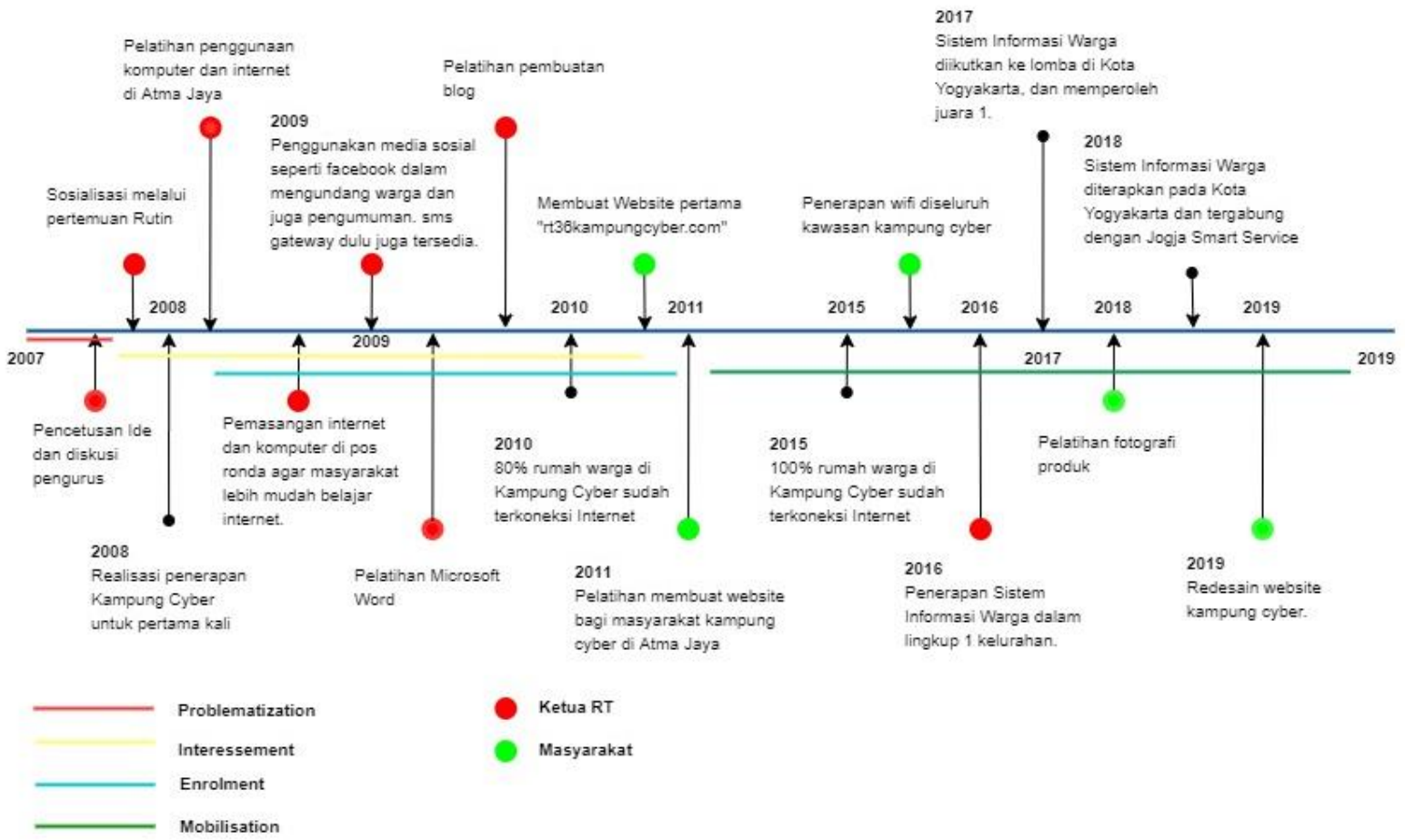

Gambar 1. Implementasi TIK di Kampung Cyber berdasarkan ANT

Pada tahun 2008 bulan Juli Kampung Cyber diresmikan. Fase enrolment dimulai ketika program pertama dari implementasi TIK dimulai yaitu pelatihan pengenalan komputer, jaringan, dan Internet bagi masyarakat. Pada tahap ini juga sebenarnya Interessement terus berjalan dengan mengajak masyarakat untuk mau belajar komputer dan Internet. Tidak hanya pada acara resmi, ketika berkumpul bersama warga Pak RT juga mengajak dan mensosialisasikan. Agenda selanjutnya adalah pemasangan komputer di pos ronda. Agenda ini juga termasuk fase enrolment dan interessment karena bertujuan untuk media belajar bagi masyarakat dan juga untuk menarik minat masyarakat yang berlum mau untuk belajar komputer dan Internet. Agenda terus berlanjut dengan pembuatan group Kampung Cyber melalui Facebook. Tujuannya sama agar masyarakat belajar untuk menggunakan sosial media dan menarik minat masyarakat yang belum mau belajar. Pada studi kasus di Kampung Cyber fase enrolment dan interessement hampir berjalan berdampingan. Pada tahun 2010 sebanyak 80\% rumah di kawasan Kampung Cyber sudah terkoneksi Internet. Pade fase itu juga bisa dikatakan mobilisation sudah dimulai karena sudah terdapat keadaan dimana masyarakat mayoritas sudah memiliki kondisi yang sama yaitu mengetahui penggunaan komputer dan Internet. Pada fase mobilisation ini ketua RT melakukan diskusi dengan masyarakat untuk menentukan program kampung cyber selanjutnya.

Pendekatan ANT adalah pendekatan analitis yang membantu membuka kotak hitam keputusan dan perebutan kekuasaan dalam proses inovasi (Andrade and Urquhart, 2010). Pada gambar 1 juga dapat dilihat bagaimana kecenderungan perubahan terhadap bagaimana program implementasi teknologi informasi di Kampung Cyber dibuat. Pada tahap awal yaitu problematisation, interesment, dan enrolment peran ketua RT lebih vital dan semakin lama semakin berkurang dalam mengatur bagaimana program dalam implementasi teknologi informasi di Kampung Cyber. Maksud dari peran Ketua RT yang vital adalah keputusan dari bentuk program yang diimplementasikan lebih berada pada Ketua RT dan pengurusannya. Berangsur-angsur peran Ketua RT lebih sebagai penampung aspirasi dan kebutuhan dari masyarakat terkait program yang dibutuhkan untuk Kampung Cyber. Sebaliknya peran masyarakat semakin besar dalam implementasi, ketika fase problematisation, interesment, dan enrolment masyarakat hanya mengikuti program implementasi 
yang sudah dibuat. Ketika fase mobilisation masyarakat yang menentukan program apa saja yang mereka butuhkan, hal ini dapat terjadi seiring wawasan terhadap TIK yang sudah luas. Keberhasilan dalam mengimplementasikan beberapa proyek dicapai dengan menerjemahkan berbagai aktor yang terlibat dalam proyek tersebut ke dalam tujuan bersama, yang disebut wajib poin perjalanan/ Obligatory point of passage (OPP) (Fornazin and Joia, 2015).

Penerjemahan tujuan dari implementasi TIK di Kampung Cyber berjalan dengan baik, hal ini dapat dilihat dari penerimaan masyarakat ketika fase interesment hingga bagaimana akhirnya masyarakat sendiri dapat menjadi penggerak dalam keberlangsungan program implementasi TIK selanjutnya. Kepentingan aktor yang berbeda namun cukup serupa membuat jaringan menjadi kuat (Braa et al., 2007).

\subsection{Batasan dan Peluang Peneltian Selanjutnya}

Penelitian ini membahas proses implementasi TIK untuk pembangunan dengan studi kasus di sebuah perkampungan dengan cakupan wilayah hanya satu RT. Dengan cakupan wilayah yang relatif kecil mungkin untuk pembagian kepengurusan dan tugas dari masing-masing aktor akan relatif sederhana. Peluang penelitian selanjutnya dengan melakukan penelitian dengan cakupan wilayah yang lebih besar dan kompleks untuk melihat bagaimana proses dan pembagian aktor-aktor yang terlibat.

Jika dilihat dari kondisi masyarakat di Kampung Cyber sendiri yang mayoritas memiliki pekerjaan sebagai wirausaha, maka program-program yang dipaparkan juga terbatas sesuai dengan pekerjaan di masyarakat Kampung Cyber. Peluang penelitian selanjutnya dapat dilakukan dengan meneliti dengan studi kasus yang lainnya dengan kondisi latar belakang masyarakat yang berbeda tentunya untuk melihat bagaimana program implementasi yang sesuai.

Berdasarkan penelitian ini juga dapat dikembangkan dengan penelitian selanjutnya yang meneliti bagaimana jika proses implementasi TIK di Kampung Cyber ini diterapkan untuk pengembangan di daerah lain.

\section{KESIMPULAN}

Proses implementasi TIK di Kampung Cyber dibagi menjadi 4 fase sesuai ANT. Pada fase problematization implementasi TIK di Kampung Cyber didasari keinginan dalam meningkatkan kesejahteraan masyarakat. Ide awal muncul melalui diskusi dengan pengurus RT. Aktor utama dalam implementasi adalah Ketua RT. Pada fase interessement dimulai dari ketua RT yang mengajak masyarakat untuk mau belajar menggunakan internet dan komputer. Rapat RT dan arisan dijadikan sarana dalam mengajak masyarakat. Fase enrolment ketika diadakannya berbagai pelatihan untuk mengajari mengedukasi masyarakat dalam penggunaan internet dan computer. Pada fase mobilization peran aktif masyarakat terhadap keberlanjutan program sudah terjadi. Pelatihan dan implementasi teknologi selanjutnya melibatkan masyarakat seperti pelatihan fotografi dan pemasangan wifi. Salah satu faktor penentu keberhasilan implementasi adalah dengan melihat kebutuhan dan karakteristik masyarakat, sehingga program/pelatihan bisa sesuai dengan masyarakat. Implementasi TIK di Kampung Cyber dapat berkelanjutan karena peran masyarakat yang menjadi lebih signifikan.

Proses implementasi TIK merupakan proses yang kompleks dan berkesinambungan. Hal tersebut dapat dilihat dari linimasa proses implementasi TIK yang sudah dilakukan di Kampung Cyber. Aktor utama dalam proses implementasi teknologi dan informasi di Kampung Cyber adalah Ketua RT. Tetapi analisis juga menunjukkan pergantian peran dalam keberlanjutan implementasi teknologi informasi dari ketua RT penentu kebijakan, lama kelamaan masyarakat menjadi penentu dan tugas ketua RT hanya sebagai fasilitator dan penjaring aspirasi.

\section{DAFTAR PUSTAKA}

AITKIN, H., 2009. Bridging the Mountainous Divide: A Case for ICTs for Mountain Women. Mountain Research and Development.

AKRICH, M., LATOUR, B. and CALLON, M., 2002. The Key to Success in Innovation Part I: The Art of Interessement. International Journal of Innovation Management, 6(2), pp.197-206.

ANDRADE, A.D. and URQUHART, C., 2010. The affordances of actor network theory in ICT for development research. Information Technology \& People, 23(4), pp.352-374.

AWOWI, J.E., 2010. Ghana Community Information Centers (CiCs) e-Governance Success or Mirage? Journal of E-Governance, 33(3), pp.157-167.

BIJKER, W.E., 1992. The social construction of fluorescent lighting, or how and artifact was invented in its diffusion stage. In: Shaping Technology/Building Society: Studies in Sociotechnical Change. Cambridge: MIT Press.

BRAA, J., HEYWOOD, A.B., HANSETH, O. and MOHAMMED, W., 2007. Developing Health Information Systems in Developing Countries: The Flexible Standards Strategy. MIS Quarterly, 31(2), pp.381-402.

CALLON, M., 1986. Some elements of a sociology of translation: domestication of the scallops and the fisherman. In: Power, Action and 
Belief. London: Routledge \& Kegan Paul.

FORNAZIN, M. and JOIA, L.A., 2015. Remontando a rede de atores na implantação de um sistema de informação em saúde. Revista de Administração de Empresas, 55(5), pp.527538.

HARRIS, R.W., 2016. How ICT4D Research Fails the Poor. Information Technology for Development, 22(1), pp.177-192.

HEEKS, R. and KANASHIRO, L.L., 2009. Telecentres in mountain regions - A Peruvian case study of the impact of information and communication technologies on remoteness and exclusion. Journal of Mountain Science, 6(4), pp.320-330.

IBRAHIM-DASUKI, S., ABBOTT, P. and KASHEFI, A., 2012. The Impact of ICT Investments on Development Using the Capability Approach: The case of the Nigerian Pre-paid Electricity Billing System. The African Journal of Information Systems, 4(1), pp.31-45.

KLEINE, D., 2010. ICT4WHAT ? - Using the Choice Framework to Operationalise the Capability Approach to Development. Journal of International Development, 22(5), pp.674692.

Komunikasi, K. dan informatika republik I., 2019. Luncurkan Desa Digital, Menkominfo: Semua Harus Bisa Rasakan Internet! [online] Available at: <https://www.kominfo.go.id/content/detail/17 952/luncurkan-desa-digital-menkominfosemua-harus-bisa-rasakaninternet/0/berita_satker> [Accessed 26 Nov. 2019].

LATOUR, B., 1992. Where are the missing masses? The sociology of a few mundane artifacts. In: Shaping Technology/Building Society: Studies in Sociotechnical Change. Cambridge: MIT Press.

LATOUR, B., 2005. Reassembling the Social An Introduction to Actor-Network-Theory Bruno Latour. In: Reassembling the Social. New York: Oxford University Press.

LAW, J. and CALLON, M., 1992. The life and death of an aircraft: a network analysis of technical change. In: Shaping Technology/Building Society: Studies in Sociotechnical Change, Cambridge: MIT Press.

LUO, M.M. and CHEA, S., 2017. Internet Village Motoman Project in rural Cambodia: bridging the digital divide. Information Technology \& People, 31(1), pp.2-20.

MARAIS, M., 2011. An analysis of the factors affecting the sustainability of ICT4D initiatives. In: ICT for development: people, policy and practice IDIA2011 Conference
Proceedings. pp.100-120.

MURDOCH, J., 1997. Inhuman / nonhuman / human: actor-network theory and the prospects for a nondualistic and symmetrical perspective on nature and society. Environment and Planning D: Society and Space, 15, pp.731-756.

PITULA, K., DYSART-GALE, D. and RADHAKRISHNAN, T., 2010. Expanding Theories of HCI: A Case Study in Requirements Engineering for ICT4D. Information Technologies and International Development, 6(1), pp.78-93.

SANNER, T.A. and SÆBØ, J.I., 2014. Paying Per Diems for ICT4D Project Participation: A Sustainability Challenge. nformation Technologies \& International Development, 10(2), pp.33-47.

SEIN, M.K., THAPA, D., HATAKKA, M. and SÆBØ, Ø., 2018. A holistic perspective on the theoretical foundations for ICT4D research. Information Technology for Development, [online] 0(4), pp.1-19.

SRIWINDONO, H. and YAHYA, S., 2012. Toward Modeling the Effects of Cultural Dimension on ICT Acceptance in Indonesia. Procedia Social and Behavioral Sciences, 65, pp.833838.

THAPA, D., 2011. The Role of ICT Actors And Networks in Development: The Case Study of A Wireless Project in Nepal. The Electronic Journal on Information Systems in Developing Countries, 49(1), pp.1-16.

THAPA, D., 2012. Exploring the Link between ICT Intervention and Human Development through a Social Capital Lens: The Case Study of a Wireless Project in the Mountain Region of Nepal. University of Agder.

UNWIN, 2009. ICT4D Information and Communication Technologies for Development. Cambridge: Cambridge University Press.

ZHENG, Y. and HOLLOWAY, R., 2019. Overview of Theories in ICT4D. (May). 
Halaman ini sengaja dikosongkan 